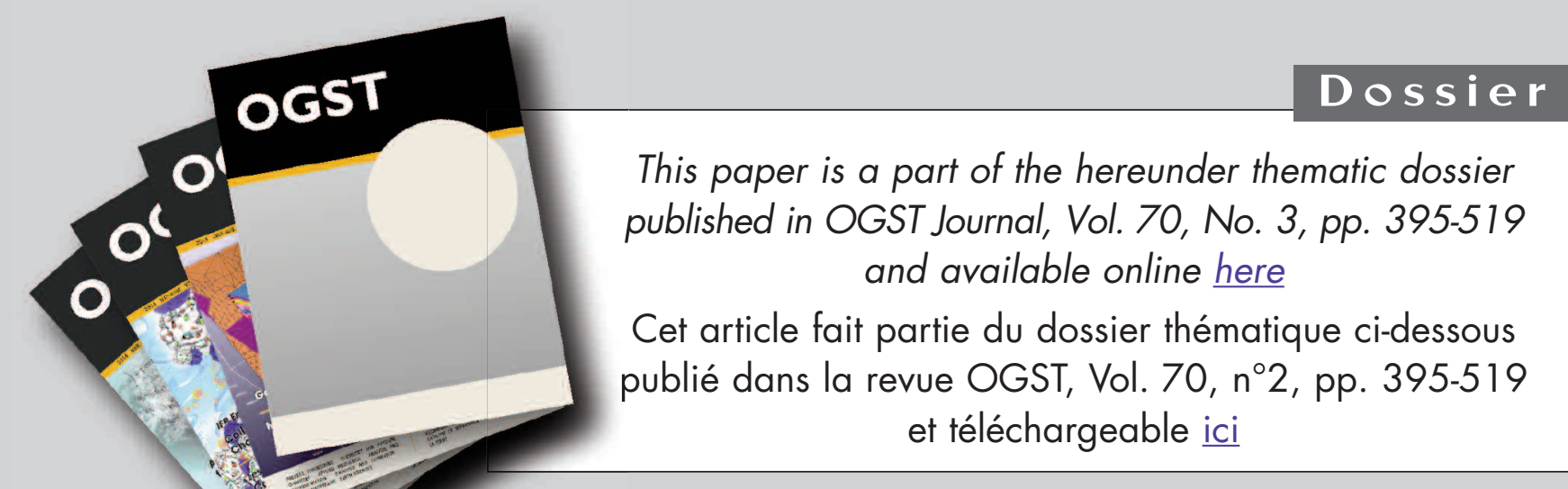

DOSSIER Edited by/Sous la direction de : V. Santos-Moreau

IFP Energies nouvelles International Conference / Les Rencontres Scientifiques d'IFP Energies nouvelles NEXTLAB 2014 - Advances in Innovative Experimental Methodology or Simulation Tools used to Create, Test, Control and Analyse Systems, Materials and Molecules

NEXTLAB 2014 - Innover dans le domaine de la méthodologie expérimentale et des outils de simulation pour créer, tester, contrôler et analyser des systèmes, matériaux et molécules

Oil \& Gas Science and Technology - Rev. IFP Energies nouvelles, Vol. 70 (2015), No. 3, pp. 395-519

Copyright (C) 2015, IFP Energies nouvelles

$395>$ Editorial - Towards the Laboratory of the Future for the Factory of the Future Éditorial - Vers le laboratoire du futur pour construire l'usine du futur V. Santos-Moreau, J.M. Newsam and J.-C. Charpentier

$405>$ Automatic and Systematic Atomistic Simulations in the MedeA ${ }^{\circledR}$ Software Environment: Application to EU-REACH

Simulations atomistiques automatiques et systématiques dans l'environnement logiciel de MedeA® : application à EU-REACH

$X$. Rozanska, P. Ungerer, B. Leblanc, P. Saxe and E. Wimmer

419 > Development of an Innovative XRD-DRIFTS Prototype Allowing Operando Characterizations during Fischer-Tropsch Synthesis over Cobalt-Based Catalysts under Representative Conditions

Développement d'un prototype DRX-DRIFTS innovant permettant des caractérisations operando de catalyseurs à base de cobalt pendant la synthèse de Fischer-Tropsch en conditions représentatives

J. Scalbert, I. Clémençon, C. Legens, F. Diehl, D. Decottignies and S. Maury

429 > Synchrotron X-ray Scattering as a Tool for Characterising Catalysts on Multiple Length Scales

La diffusion des rayons $X$ synchrotron : un outil pour la caractérisation des catalyseurs sur les multiples échelles de longueur

J.M. Hudspeth, K.O. Kvashnina, S.A.J. Kimber and E.P. Mitchell

437 > High Throughput Experimentation (HTE) Directed to the Discovery,

Characterization and Evaluation of Materials

Expérimentation à haut débit pour la découverte, la caractérisation et

l'évaluation des matériaux

J.M. Newsam

447 > The Use of Original Structure-Directing Agents for the Synthesis of EMC-1 Zeolite L'utilisation d'agents structuraux originaux pour la synthèse de zéolithe EMC-1

T.J. Daou, J. Dhainaut, A. Chappaz, N. Bats, B. Harbuzaru, H. Chaumeil, A. Defoin,

L. Rouleau and J. Patarin
455 > REALCAT: A new Platform to Bring Catalysis to the Lightspeed REALCAT : une nouvelle plate-forme pour mener la catalyse à la vitesse de la lumière

S. Paul, S. Heyte, B. Katryniok, C. Garcia-Sancho, P. Maireles-Torres and F. Dumeignil

$463>$ What are the Needs for Process Intensification? Quels besoins pour intensifi er un procédé ?

C. Gourdon, S. Elgue and L. Prat

$475>$ Revisiting the Side Crushing Test Using the Three-Point Bending Test for the Strength Measurement of Catalyst Supports

Test d'écrasement grain à grain revisité à l'aide du test de flexion trois points pour la mesure de la résistance des supports de catalyseurs D. Staub, S. Meille, V. Le Corre, J. Chevalier and L. Rouleau

487 > Refractometric Sensing of Heavy Oils in Fluorescent Core Microcapillaries La détection réfractométrique des huiles lourdes dans les microcapillaires à cœur fluorescents

V. Zamora, Z. Zhang and A. Meldrum

497 > Two-Phase Flow in Pipes: Numerical Improvements and Qualitative Analysis for a Refining Process

Écoulements diphasiques dans les conduites : améliorations numériques et analyse qualitative pour un procédé de raffinage

R.G.D. Teixeira, A.R. Secchi and E.C. Biscaia Jr

511 > Comparative TPR and TPD Studies of Cu and Ca Promotion on Fe-Zn- and Fe-Zn-Zr-Based Fischer-Tropsch Catalysts

Études comparatives par TPR et TPD de la promotion par Cu et Ca de I'activité de catalyseurs Fischer-Tropsch Fe-Zn et Fe-Zn-Zr 0.0 . James, B. Chowdhury and S. Maity 
NEXTLAB 2014 - Advances in Innovative Experimental Methodology or Simulation Tools used to Create, Test, Control and Analyse Systems, Materials and Molecules

NEXTLAB 2014 - Innover dans le domaine de la méthodologie expérimentale et des outils de simulation pour créer, tester, contrôler et analyser des systèmes, matériaux et molécules

\title{
Synchrotron X-Ray Scattering as a Tool for Characterising Catalysts on Multiple Length Scales
}

\author{
Jessica M. Hudspeth ${ }^{1 *}$, Kristina O. Kvashnina ${ }^{1}$, Simon A.J. Kimber ${ }^{1}$ and Edward P. Mitchell ${ }^{2}$ \\ ${ }^{1}$ European Synchrotron Radiation Facility, 71 avenue des Martyrs, 38000 Grenoble - France \\ 2 Business Development Office, European Synchrotron Radiation Facility, 71 avenue des Martyrs, 38000 Grenoble - France \\ e-mail: hudspeth@esrf.fr - industry@esrf.fr \\ * Corresponding author
}

\begin{abstract}
Optimising the properties of catalysts for industrial processes requires a detailed knowledge of their structure and properties on multiple length scales. Synchrotron light sources are ideal tools for characterising catalyts for industrial $R \& D$, providing data with high temporal and spatial resolution, under realistic operating conditions, in a non-destructive way. Here, we describe the different synchrotron techniques that can be employed to gain a wealth of complementary information, and highlight recent developments that have allowed remarkable insight to be gained into working catalytic systems. These techniques have the potential to guide future industrial catalyst design.
\end{abstract}

\begin{abstract}
Résumé - La diffusion des rayons $X$ synchrotron : un outil pour la caractérisation des catalyseurs sur les multiples échelles de longueur - Afin d'optimiser les propriétés des catalyseurs pour les processus industriels, il est nécessaire d'avoir une profonde connaissance de leurs structures et propriétés sur les multiples échelles de longueurs. Les sources de lumière synchrotron sont les outils idéaux pour la caractérisation des catalyseurs dans la R\&D industrielle. Ils permettent d'étudier des processus catalytiques avec une haute résolution spatiale et temporelle, dans des conditions opératoires réelles, de façon non destructive. Nous décrivons ici les différentes méthodes synchrotrons qui peuvent être utilisées pour obtenir une grande quantité des données complémentaires, et souligner quelques développements récents avec lesquels on a gagné de nouvelles connaissances remarquables. Ces méthodes ont le potentiel de guider la conception des catalyseurs industriels du futur.
\end{abstract}




\section{INTRODUCTION}

The intelligent design of catalysts is key to effective and energy efficient processes. Optimising the properties of these catalysts, which are used widely across all areas of industry, including the oil and gas industry, requires intimate understanding of their atomic structure [1]. Recent advances in controlling materials structure and properties at the nanoscale mean that this is the key length scale [2-4]. A further challenge is the coupling of this structure with properties on the micrometre length scale, for example porosity in catalysts supports, or optimising the spatial distribution of an active ingredient. Finally, characterisation tools must not only be able to probe multiple length scales, but should be non-destructive and able to detect changes under realistic operating conditions. In this short review, we argue that synchrotron $\mathrm{X}$-ray sources such as the European Synchrotron Radiation Facility (ESRF) in Grenoble, France, provide a unique combination of these attributes. Furthermore, these facilities are available for both blue sky fundamental research, as well as proprietary commercial applications.

In brief, a synchrotron X-ray source consists of a powerful particle accelerator (the ESRF operates with relativistic $6.05 \mathrm{GeV}$ electrons). These particles are injected into a circular storage ring and lose energy by producing a broad spectrum of light, from the IR to gamma rays. Multiple measurement stations, or beamlines, view the X-ray source at tangents to the ring, and each is optimised for a different type of measurement. Synchrotrons are large scale facilities (the circumference of the ESRF storage ring is ca. $800 \mathrm{~m}$ ), and are funded by national governments or international consortia. In the case of the ESRF, twenty one countries contribute funding.
Synchrotron X-rays have numerous advantages for studying catalytic processes under realistic operating conditions. The high energy X-rays produced by synchrotron sources can penetrate bulky or dense samples and sample environments. High brilliance allows measurements to be performed with high spatial and temporal resolution, making them ideal for in situ, time resolved studies of chemical processes. In addition, the X-ray energies can be tuned to perform element specific measurements and speciation studies.

\section{TECHNIQUES}

A variety of synchrotron X-ray techniques can be employed to provide valuable information about the structure and properties of catalytic systems on different lengths scales. The complementary nature of the information obtained by different methods means that it is often useful to use multiple techniques to obtain a complete understanding of the catalytic process of interest. A selection of synchrotron X-ray techniques and the information that can be obtained from them are described below, and summarised in Table 1, along with the relevant beamlines that perform these techniques at ESRF.

\subsection{X-Ray Powder Diffraction (XRPD)}

XRPD can be used to identify, refine the structure, and quantify the relative fraction of crystalline phases in a sample. For in situ catalysis studies XRPD can provide valuable insight into the reaction pathways and intermediate phases [5-9]. Since only average structure information is obtained, it is often useful to combine XRPD with a local structure

TABLE 1

A summary of the information that can be gained from the various synchrotron X-ray techniques and the relevant beamlines at ESRF for catalysis studies

\begin{tabular}{l|l|l}
\multicolumn{1}{c|}{ Information of interest } & \multicolumn{1}{c}{ Technique } & \multicolumn{1}{c}{ Beamlines } \\
\hline $\begin{array}{l}\text { Identification, quantification and structural } \\
\text { refinement of crystalline phases }\end{array}$ & X-ray powder diffraction & $\begin{array}{l}\text { High resolution: ID22, BM01, BM25 } \\
\text { Standard: ID11, ID15, BM26 }\end{array}$ \\
\hline Structure of surface phases & Surface X-ray diffraction & ID03 \\
\hline $\begin{array}{l}\text { Identification and quantification of nano- } \\
\text { crystalline and amorphous phases }\end{array}$ & Pair distribution function analysis & ID15, ID22, ID11 \\
\hline $\begin{array}{l}\text { Spatial distribution of crystalline phases and } \\
\text { crystallite sizes }\end{array}$ & X-ray diffraction computed tomography & ID15, ID11 \\
\hline $\begin{array}{l}\text { Spatial distribution of amorphous phases and } \\
\text { nanoparticle sizes }\end{array}$ & Pair distribution function computed tomography & ID15 \\
\hline $\begin{array}{l}\text { Local environment and chemical bonding } \\
\text { around a specific element }\end{array}$ & $\begin{array}{l}\text { X-ray absorption spectroscopy: EXAFS, } \\
\text { XANES }\end{array}$ & $\begin{array}{l}\text { ID26, ID24, ID21, BM01, BM08, BM23, BM25, } \\
\text { BM30, BM26 }\end{array}$ \\
\hline Spatial distribution of a specific element & X-ray fluorescence & ID16, ID21, ID13 \\
\hline
\end{tabular}


technique such as pair distribution function analysis or X-ray absorption spectroscopy (described below).

\subsection{Surface X-Ray Diffraction (SXRD)}

Understanding the surface structure of heterogeneous catalysts is particularly important since exposure to reactants can cause entirely new structures to form. These structures can strongly influence the reaction by, for example, "poisoning" or by acting as the active phase. In situ SXRD studies have provided new insight into the surface structures formed and their role in catalytic reactions [10-12].

\subsection{X-Ray Diffraction Computed Tomography (XRD-CT)}

For heterogeneous catalysis, controlling the nature and distribution of the active phases, particularly at operating temperatures and conditions, is crucial for optimising catalytic performance. Hence, it is important not only to quantify the phases present but also to be able to map their spatial distribution in 2D and 3D. This has been achieved by the development of XRD-CT (Fig. 1) which can be used to map the distribution of phases with micrometre resolution in a time-resolved manner $[14,15]$. The crystallite size distribution can also be mapped by using the diffraction peak widths.

\subsection{Pair Distribution Function (PDF) Analysis}

Many catalytic processes rely on nanoscale structures (e.g. metallic nanoparticles on porous support material) making

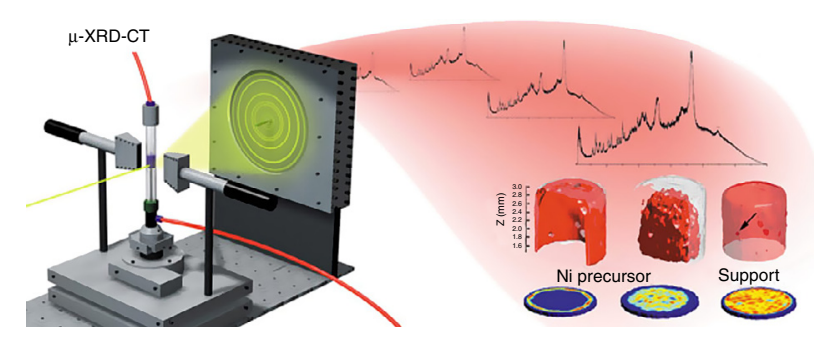

Figure 1

In XRD-CT a series of transmission projection measurements is made at different rotation angles while the sample is exposed to $\mathrm{X}$-ray radiation. A $2 \mathrm{D}$ image slice is then reconstructed from these measurements using an algorithm based on the difference in the diffraction signal for the crystalline phases present. Adapted from Reference [14] with permission from The Royal Society of Chemistry. local structure information essential for optimising performance. PDF analysis is a valuable tool for the study of nanocrystalline materials [16] and has been used to investigate a variety of catalytic systems [17-19]. PDF analysis gives the probability of finding any two atoms at a given interatomic distance in real space. It is a total scattering technique and provides information on both local and intermediate length scales (10-20 ̊). PDF analysis can be used to identify and quantify the amorphous and nanocrystalline phases present in the sample as well as obtaining information about nanoparticle size.

\subsection{Pair Distribution Function Computed Tomography (PDF-CT)}

Similarly to XRD-CT, PDF analysis can be coupled with computed tomography to investigate the distribution of nanocrystalline and amorphous phases [20]. The data obtained by PDF-CT enables physicochemical profiling of the nanoscale properties of materials and their distribution with $\mu \mathrm{m}$ resolution.

\subsection{X-Ray Absorption Spectroscopy (XAS)}

XAS is an element specific technique that determines the local environment and chemical state of the absorbing atom and has been applied to a wide variety of catalytic systems [21-24]. Samples can be in the gas, liquid or solid phase. Hard X-ray absorption spectroscopy is particularly useful since it does not require a high-vacuum environment around the sample making it suitable for in situ reactions studies at realistic operating conditions.

XAS data are collected by tuning the photon energy to a particular energy range where the core electrons from $1 \mathrm{~s}, 2 \mathrm{p}$, $3 \mathrm{~d}$, etc., can be excited. There are three main regions which can be recorded by XAS: pre-edge region, main-edge region and post-edge region (Fig. 2). Spectra recorded at the preedge and the main-edge regions are known as X-ray Absorption Near-Edge Structure (XANES). Measurements of the post-edge transitions are known as Extended X-ray Absorption Fine Structure (EXAFS). XANES is useful for determining the chemical state while EXAFS can be employed for understanding the local structure.

\subsection{X-Ray Fluorescence (XRF)}

XRF techniques can be used to map the spatial distribution of the fluorescing element. For catalysis, this can provide valuable information about, for example, the loss of active elements and the retention of contaminating elements $[15,25,26]$. Using synchrotron XRF, trace elements can be detected with concentrations down to the attogram and their distributions mapped with nanometre scale resolution. 


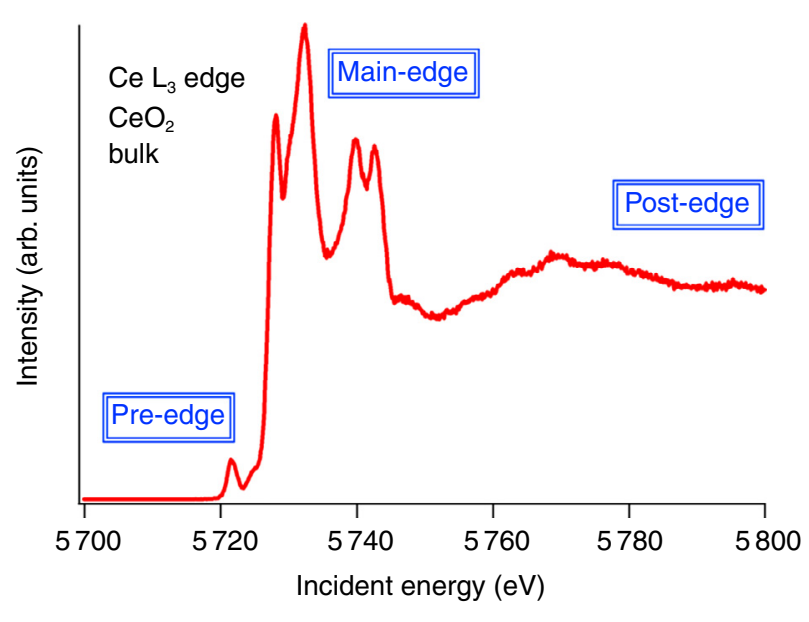

Figure 2

The pre-edge, main-edge and post-edge regions of an XAS spectrum for the $\mathrm{Ce}_{3}$ edge in $\mathrm{CeO}_{2}$.

\subsection{Sample Environments}

A variety of sample environments are available for performing experiments in situ with realistic operating conditions. These include gas flow cells and gas pressure systems with static loadings of up to 200 bar [27, 28]. Temperatures ranging from 4 to $1800 \mathrm{~K}$ are accessible using a variety of ancillary equipment. Custom built sample environments can also be produced for specific applications to match academic and industrial research needs. Further, there is the capability to combine X-ray measurements with other techniques such as Raman spectroscopy and mass spectrometry to gain additional in situ complementary information about the system $[28,29]$.

\section{INDUSTRY}

Characterisation is at the heart of modern industrial materials R\&D, feeding materials innovation and process refinement. As such, industry is a growing user and partner of synchrotron facilities - both for routine characterisation needs and for more complex R\&D requirements, and from Technology Readiness Levels (TRL) spanning precompetitive work up to operational and production issues $[30,31]$. This potential was recognised even at the outset of synchrotron light development in the 1940s [32]. Nowadays, most synchrotron light sources operate an in-house business development or industry liaison office whose mission is to build interactions with industry through flexible and rapid paid-for proprietary access, collaborations and partnerships, and free peer review access where the work is publishable.

In the domain of catalysts, screening of catalyst structure and components is made feasible and cost effective using high-throughput measurements with high energy X-rays, such as for PDF, and tunable X-rays for spectroscopy. Sometimes longer-term $R \& D$ projects require novel sample environments and more complex experiments and data analysis. In these cases, industry can come forward with funding for $\mathrm{PhD}$ students or even a staff exchange to allow internal knowledge of the techniques and facilities to be built up.

With the growing impact of synchrotron light in industry, nimble start-up companies are helping to bridge the gap between the facilities and industrial clients. Examples include Finden (UK), Novitom (France), Colloidal Resources (Sweden) and Excelsus (Belgium). These, together with academic partners, allow the business and industrial offices to best respond to industrial R\&D needs. Europe has also realised the power of such central facilities, with a number of opportunities being put forward by community-led integrating activities and industrially directed public-private partnerships in the Horizon 2020 programme, which is aiming to build a bridge across the traditional divide between academia and business.

\section{EXAMPLES}

\subsection{Example 1: In Situ Reduction Study of Cobalt Model Fisher-Tropsch Synthesis Catalyst [7]}

Fischer-Tropsch (FT) synthesis, developed in 1925, is an important industrial process still used today to produce a variety of liquid hydrocarbons from a mixture of carbon monoxide and hydrogen. $\mathrm{Al}_{2} \mathrm{O}_{3}$ supported cobalt oxide phases are commonly used as catalyst precursors but must undergo a reduction or activation treatment before FT synthesis can occur. Understanding the reaction pathway and intermediates is important for improving the performance of industrial cobalt based catalysts.

Sasol investigated the reduction process of a model $\mathrm{Co} / \mathrm{Al}_{2} \mathrm{O}_{3}$ catalyst (Co oxide phases deposited on micrometre $\gamma-\mathrm{Al}_{2} \mathrm{O}_{3}$ support particles shown in Fig. 3) under realistic conditions using in situ synchrotron high resolution XRPD. In addition to conventional XRPD analysis, total scattering (PDF) analysis was employed to probe the local structure changes.

Figure 3 shows the evolution of the XRPD patterns collected with increasing temperature and time during reduction under a flow of $\mathrm{H}_{2}$ at ambient pressure. The $\mathrm{Co}_{3} \mathrm{O}_{4}$ was completely reduced to $\mathrm{CoO}$ by $240^{\circ} \mathrm{C}$. The reduction of 


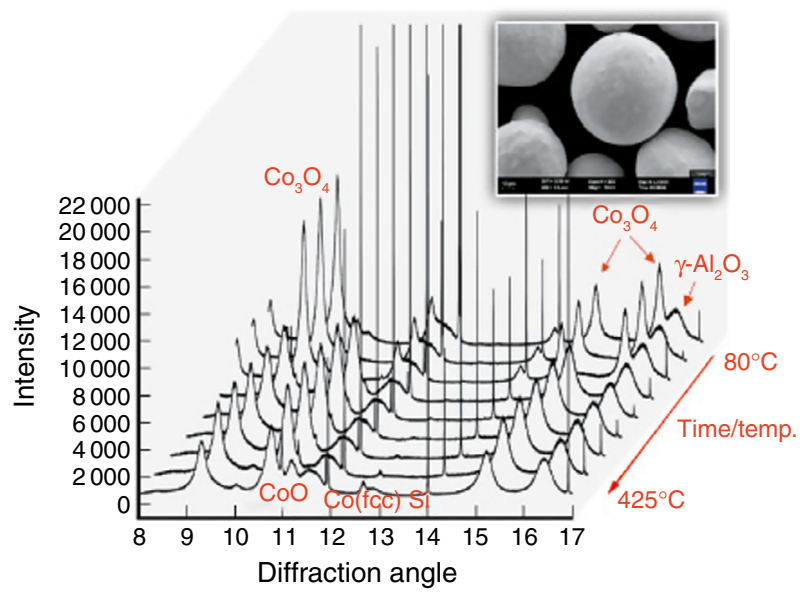

Figure 3

The experimental diffractograms during reduction of the Co oxide phases under $5 \% \mathrm{H}_{2}$ from $80^{\circ} \mathrm{C}$ to $425^{\circ} \mathrm{C}$ indicating, in particular, the peaks from the $\mathrm{Si}$ reference (very narrow), and the evolution of the cobalt oxides to metallic cobalt. The inset shows one of the $\mathrm{Al}_{2} \mathrm{O}_{3}$ particles $(\sim 80 \mu \mathrm{m})$ on which the cobalt oxides are deposited. Adapted from Reference [7] with permission from the PCCP Owner Societies.

$\mathrm{CoO}$ to cobalt metal proceeded more slowly and the reduction in the $\mathrm{CoO}$ abundance coincided with an increase in both the Co metallic and amorphous phase fractions.

The quantification of the amorphous Co phase was beyond the limits of the XRPD analysis but all of the Co present could be accounted for by the PDF analysis which showed that mainly face-centred cubic (fcc) Co metal remained after reduction. The combination of PDF with standard XRPD analysis therefore provided a more complete understanding of the evolution of the Co containing phases in the catalyst particles. This approach could be used to provide additional insight into many other processes.

\subsection{Example 2: Catalyst Active Phase Evolution from $\mathrm{X}$-Ray Diffraction Computed Tomography [13]}

Metals and metal oxides anchored to porous support materials are used extensively as heterogeneous catalysts in industrial processes. They are often employed as millimetre sized catalyst bodies and the efficiency of the catalytic system depends on the nature and distribution of the active phases. Understanding the factors that influence the distribution during the preparation is crucial for optimising the design and performance.

Time resolved XRD-CT was used to examine a Ni supported $\gamma-\mathrm{Al}_{2} \mathrm{O}_{3}$ catalyst body during the calcination stage

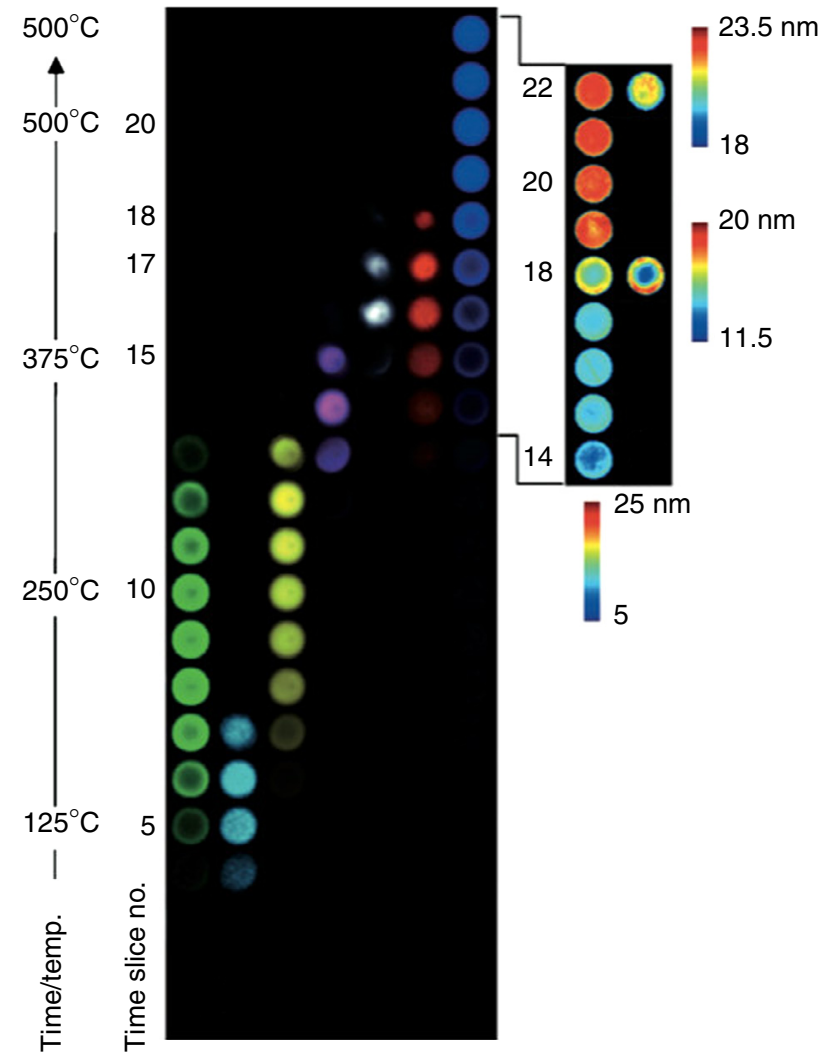

Figure 4

Reconstructed 2D images of crystalline components' features observed in the diffraction patterns as a function of time/ temperature during thermal activation of a $\gamma-\mathrm{Al}_{2} \mathrm{O}_{3}$-supported $\mathrm{Ni}$ catalyst precursor. a) The colour maps indicate the following distribution of solid-state phases: precursor 1 (green), precursor 2 (cyan), subsequent breakdown phases associated with precursor 2 (yellow, magenta, white and red), and fcc Ni (blue). b) The thermal colour maps show the variation in crystallite size $(\mathrm{nm})$. When plotted with a common colour axis (shown beneath) these indicate the growth of fcc Ni crystallite size as the growth of the phase proceeds. For slices 18 and 22, the data have been re-plotted with bespoke colour axes (right). Reprinted from Reference [13], Copyright 2011, with permission from Wiley- $\mathrm{VCH}$.

of the preparation process. These catalysts are widely employed for hydrogenation reactions. The cylindrical catalyst body was impregnated with a $\mathrm{Ni}$ catalyst precursor material and calcination was performed under $\mathrm{N}_{2}$.

Figure 4 shows the evolution of the Ni containing phases during the calcination process. Two routes to the formation of metallic fcc Ni active phase from two different decompositions of the precursor were observed, with one precursor phase located at the periphery and the other located in the centre. Although both phases lead to the formation of the active fcc phase, the edge precursor did so in a one step process whereas the centre precursor took three to four steps. 
The two different processes also lead to different particle sizes of the fcc $\mathrm{Ni}$, with larger particle sizes in the centre than at the periphery, which is important for the activity/selectivity of the catalyst body in a reaction.

The new information that can be gained from XRD-CT could have important implications for developing better control over the particle size and distribution of the active species and ultimately lead to improved catalytic performance.

\subsection{Example 3: Pair Distribution Function Computed Tomography [20]}

Catalytic materials are often most effective when deposited in nanocrystalline form. Being able to track the distribution of such phases is therefore important for optimising performance but is largely beyond the limits of XRDCT. PDF analysis can be used to study nanocrystalline and amorphous materials so combining PDF analysis with CT allows nano-structural information to be mapped and quantified.

Pd catalysts are used as the active component in both hydrogenation and oxidation reactions. Both XRD-CT and PDF-CT were used to investigate the distribution of $\mathrm{Pd}$ loaded in $\gamma-\mathrm{Al}_{2} \mathrm{O}_{3}$ industrial catalyst bodies during calcination and reduction in $5 \% \mathrm{H}_{2} / \mathrm{Ar}$.

Figure 5a shows the reconstructed distributions of PdO and fcc Pd under reducing conditions from both the XRD$\mathrm{CT}$ and PDF-CT measurements. The distributions were determined based on characteristic peaks in the XRPD and PDF measurments for the two phases. In the XRDCT map, only the fcc Pd phase appears to be present and is predominantly located at the edge of the catalyst body. In contrast, the PDF-CT map, while consistent with the XRD-CT result, also shows some additional intensity within the main body of the sample from both $\mathrm{PdO}$ and $\mathrm{Pd}$, indicating the presence of "diffraction silent" nanomaterial.

Additional quantitative analysis of representative PDF from voxels at the periphery and in the core, shown in Figure $5 \mathrm{~b}$, was used to verify the observation of "diffraction silent" Pd. The PDF signal from the "diffraction silent" nanoparticles in the centre of the catalyst body dies out very quickly suggesting these nanoparticles must be very small. Using a spherical approximation for the shape of the nanoparticles in the PDF calculations, a good fit was obtained with a nanoparticle diameter of $\sim 1.4 \mathrm{~nm}$ the catalyst body centre, whereas those at the edge exceed $\sim 4 \mathrm{~nm}$.

The ability to detect "diffraction silent" materials means that PDF-CT can provide a more complete picture of the evolution of different species within the catalyst body than XRD-CT, making it a promising technique for developing

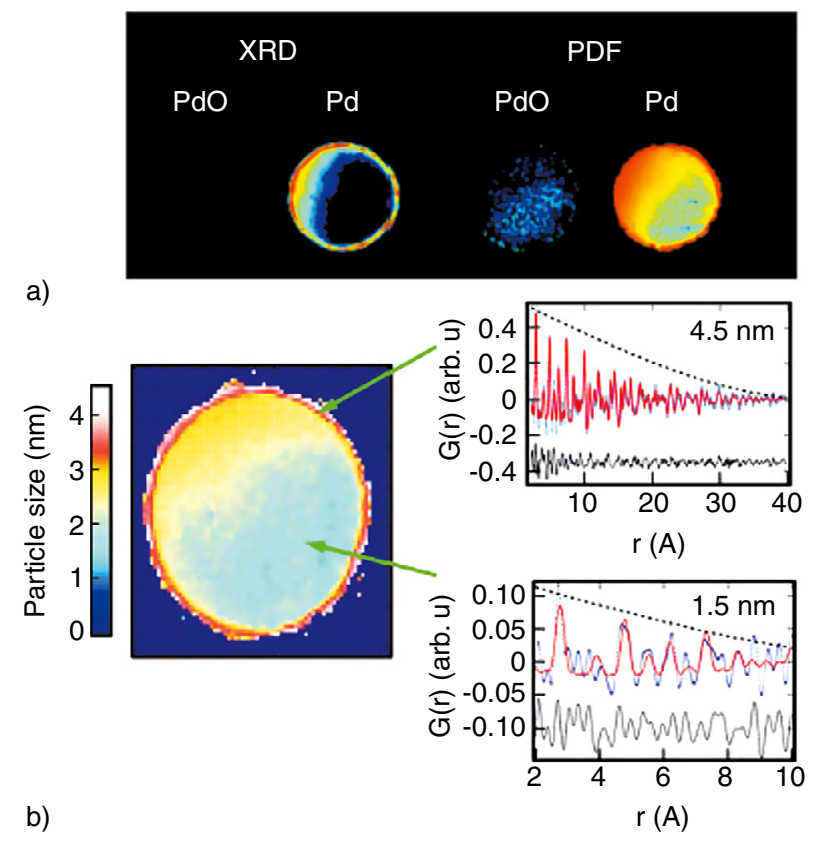

Figure 5

a) Comparison of the information from XRD-CT (left) and PDF-CT (right) after sample reduction. b) Distribution of particle sizes of fcc Pd within the catalyst body under reducing conditions and portions of the PDF data for selected pixels at the edge and interior of the catalyst body. Adapted and reprinted by permission from Macmillan Publishers Ltd from Reference [20], copyright 2013.

more robust structure-activity relationships in real catalyst samples and guiding catalyst design.

\subsection{Example 4: In Situ XANES Study of Catalytically Active $\mathrm{CeO}_{2}$ Nanoparticles [24]}

Cerium dioxide $\left(\mathrm{CeO}_{2}\right)$ nanoparticles or nanoceria are unique and multifunctional materials with a wide range of applications in catalysis, photochemistry and biomedicine. These applications appear to rely on the capability of nanoceria to store or release oxygen through conversion between $\mathrm{Ce}$ (IV) and $\mathrm{Ce}$ (III) formal oxidation states. In order to understand the performance of $\mathrm{CeO}_{2}$ nanoparticles in materials applications, a large number of studies has been dedicated to their catalytic activity, chemical reactivity, and electronic and structural properties in relation to different synthesis techniques.

In a recent in situ study, high energy resolution XANES at the $\mathrm{Ce} \mathrm{L}_{3}$ edge was used to investigate the chemical state of $\mathrm{Ce}$ during the conversion of $\mathrm{Ce}\left(\mathrm{NO}_{3}\right)_{3} \cdot 6 \mathrm{H}_{2} \mathrm{O}$ into $\mathrm{CeO}_{2}$ nanoparticles. Performing such experiments in situ is particularly important since the electronic structure of nanoceria is critically dependent on the reaction environment. 


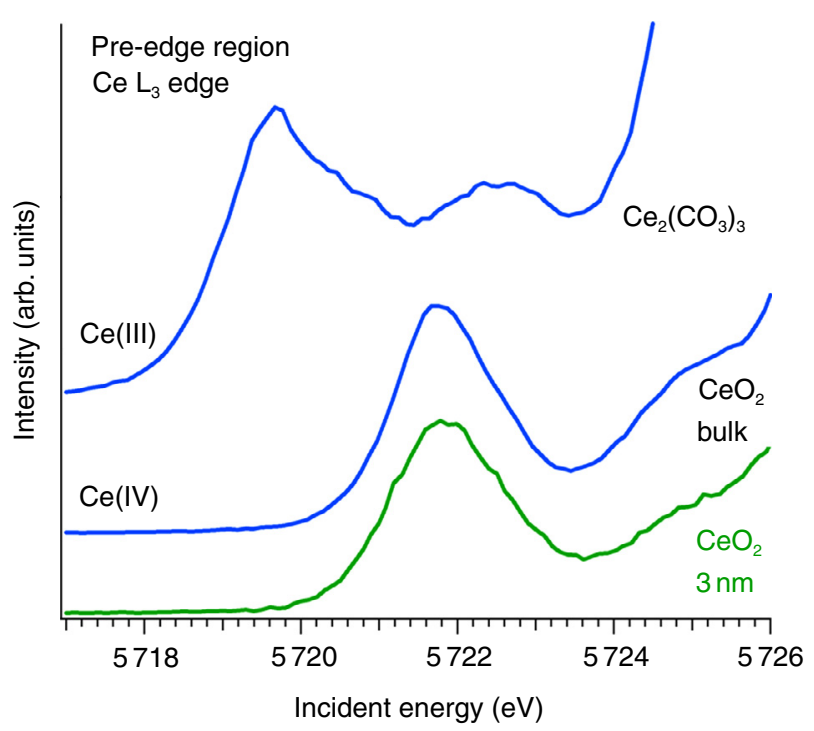

Figure 6

Examples of the pre-edge transitions recorded at the $\mathrm{Ce}_{3}$ edge for cerium model systems in two different oxidation states, $\mathrm{Ce}(\mathrm{III})$ and $\mathrm{Ce}(\mathrm{IV})$, in bulk samples $\left(\mathrm{Ce}_{2}\left(\mathrm{CO}_{3}\right)_{3}\right.$ and $\mathrm{CeO}_{2}$ respectively) along with the spectrum for the synthesised $3 \mathrm{~nm} \mathrm{CeO}$ nanoparticles.

Figure 6 shows an example of the pre-edge transitions recorded at the $\mathrm{Ce} \mathrm{L}_{3}$ edge for bulk $\mathrm{Ce}_{2}\left(\mathrm{CO}_{3}\right)_{3}$ and bulk $\mathrm{CeO}_{2}$ which have oxidation states of $\mathrm{Ce}(\mathrm{III})$ and $\mathrm{Ce}(\mathrm{IV})$ respectively. The spectrum for the synthesised $3 \mathrm{~nm} \mathrm{CeO} 2$ nanoparticles is also shown. The shape and the energy position of the pre-edge structure in the nanoceria spectrum are similar to features for bulk $\mathrm{CeO}_{2}(\mathrm{Ce}(\mathrm{IV}))$.

It was concluded that the formation of $\mathrm{Ce}(\mathrm{III})$ sites is not necessarily to account for the chemical activity of nanoceria, contrary to that which had previously been assumed based on ex situ experiments. These results highlight the complexity of the electronic structure in nanoceria and the importance of performing experiments under realistic operating conditions.

\section{CONCLUSION}

Synchrotron light is a unique probe for observing catalyst materials, providing detailed spatially and temporally resolved data on catalysts in action under real working conditions. The progress in this area in the last years has been remarkable, with new developments bringing together $\mathrm{X}$-ray techniques such as tomography and PDF or powder diffraction to provide unprecedented insights into working catalysts. Synchrotron light facilities are combining more than just X-rays, adding complementary data with Raman and mass spectroscopy.

The field has enormous potential in industry to make application to catalyst tailoring and development more efficient. With light sources being increasingly open and accessible for industrial $\mathrm{R} \& \mathrm{D}$, the impact of the results coming out from such experiments, for industry and on the economy, is only just starting to be seen.

\section{REFERENCES}

1 Iglesias-Juez A., Beale A.M., O’Brien M.G., Newton M.A., Bras W., Weckhuysen B.M. (2009) Multi-Technique In situ Approach Towards the Study of Catalytic Solids at Work Using Synchrotron Radiation, Synchrotron Radiation News 22, 1 , 22-30.

2 Bell A.T. (2003) The Impact of Nanoscience on Heterogeneous Catalysis, Science 299, 5613, 1688-1691.

3 Li Y., Somorjai G.A. (2010) Nanoscale Advances in Catalysis and Energy Applications, Nano Letters 10, 7, 2289-2295.

4 Zäch M., Hägglund C., Chakarov D., Kasemo B.B. (2006) Nanoscience and nanotechnology for advanced energy systems, Current Opinion in Solid State and Materials Science 10, 3-4, 132-143.

5 Hargreaves J.S.J. (2005) Powder X-ray diffraction and heterogeneous catalysis, Crystallography Reviews 11, 1, 21-34.

6 Rodriguez J.A., Hanson J.C., Wen W., Wang X., Brito J.L., Martínez-Arias A., Fernández-García M. (2009) In-situ characterization of water-gas shift catalysts using time-resolved X-ray diffraction, Catalysis Today 145, 3-4, 188-194.

7 du Plessis H.E., Forbes R.P., Barnard W., Erasmus W.J, Steuwer A. (2013) In situ reduction study of cobalt model Fischer-Tropsch synthesis catalysts, Phys. Chem. Chem. Phys. 15, 11640-11645.

8 Wragg D.S., Akporiaye D., Fjellvåg H. (2011) Direct observation of catalyst behaviour under real working conditions with X-ray diffraction: Comparing SAPO-18 and SAPO-34 methanol to olefin catalysts, Journal of Catalysis 279, 2, 397-402.

9 Newton M.A., Di Michiel M., Kubacka A, Fernández-García M. (2010) Combining Time-Resolved Hard X-ray Diffraction and Diffuse Reflectance Infrared Spectroscopy To Illuminate CO Dissociation and Transient Carbon Storage by Supported Pd Nanoparticles during CO/NO Cycling, Journal of the American Chemical Society 132, 13, 4540-4541.

10 Hendriksen B.L.M., Ackermann M.D., van Rijn R., Stoltz D., Popa I., Balmes O., Resta A., Wermeille D., Felici R., Ferrer S., Frenken J.W.M. (2010) The role of steps in surface catalysis and reaction oscillations, Nat. Chem. 2, 9, 730-734.

11 Farkas A., Zalewska-Wierzbicka K., Bachmann C., Goritzka J., Langsdorf D., Balmes O., Janek J., Over H. (2013) High Pressure Carbon Monoxide Oxidation over Platinum (111), The Journal of Physical Chemistry C 117, 19, 9932-9942.

12 Balmes O., van Rijn R., Wermeille D., Resta A., Petit L., Isern H., Dufrane T., Felici R. (2009) The ID03 surface diffraction beamline for in-situ and real-time X-ray investigations of catalytic reactions at surfaces, Catalysis Today 145, 3-4, 220-226. 
13 Jacques S.D.M., Di Marco M., Beale A.M., Sochi T., O’Brien M.G., Espinosa-Alonso L., Weckhuysen B.M., Barnes P. (2011) Dynamic X-Ray Diffraction Computed Tomography Reveals Real-Time Insight into Catalyst Active Phase Evolution, Angewandte Chemie International Edition 50, 43, 10148-10152.

14 O’Brien M.G., Jacques S.D.M., Di Michiel M., Barnes P., Weckhuysen B.M., Beale A.M. (2012) Active phase evolution in single $\mathrm{Ni} / \mathrm{Al}_{2} \mathrm{O}_{3}$ methanation catalyst bodies studied in real time using combined $\mu$-XRD-CT and $\mu$-absorption-CT, Chem. Sci. 3, 509-523.

15 Beale A.M., Gibson E.K., O’Brian M.G., Jacques S.D., Cernik R.J., Di Michiel M., Cobden P.D., Pirgon-Galin Ö., van de Water L., Watson M.J., Weckhuysen B.M. (2014) Chemical imaging of the sulfur-induced deactivation of $\mathrm{Cu} / \mathrm{ZnO}$ catalyst bodies, Journal of Catalysis 314, 94-100.

16 Billinge S.J. (2008) Nanoscale structural order from the atomic pair distribution function (PDF): There's plenty of room in the middle, Journal of Solid State Chemistry 181, 7, 1695-1700.

17 Chupas P.J., Chapman K.W., Chen H., Grey C.P. (2009) Application of high-energy X-rays and Pair-Distribution-Function analysis to nano-scale structural studies in catalysis, Catalysis Today 145, 3-4, 213-219.

18 Newton M.A., Chapman K.W., Thompsett D., Chupas P.J. (2012) Chasing Changing Nanoparticles with Time-Resolved Pair Distribution Function Methods, Journal of the American Chemical Society 134, 11, 5036-5039.

19 Du P., Kokhan O., Chapman K.W., Chupas P.J., Tiede D.M. (2012) Elucidating the Domain Structure of the Cobalt Oxide Water Splitting Catalyst by X-ray Pair Distribution Function Analysis, Journal of the American Chemical Society 134, 27, 11096-11099. PMID: 22720737.

20 Jacques S.D.M., Di Michiel M., Kimber S.A.J., Yang X., Cernik R.J., Beale A.M., Billinge S.J.L. (2013) Pair distribution function computed tomography, Nature Communications 4, 2536.

21 Bordiga S., Groppo E., Agostini G., van Bokhoven J.A., Lamberti C. (2013) Reactivity of Surface Species in Heterogeneous Catalysts Probed by In situ X-ray Absorption Techniques, Chemical Reviews 113, 3, 1736-1850.

22 Grunwaldt J.-D., Caravati M., Hannemann S., Baiker A. (2004) X-ray absorption spectroscopy under reaction conditions: suitability of different reaction cells for combined catalyst characterization, time-resolved studies, Phys. Chem. Chem. Phys. 6, 3037-3047.

23 Nagai Y., Dohmae K., Ikeda Y., Takagi N., Tanabe T., Hara N., Guilera G., Pascarelli S., Newton M.A., Kuno O., Jiang H., Shinjoh H., Matsumoto S. (2008) In situ Redispersion of Platinum Autoexhaust Catalysts: An On-Line Approach to Increasing Catalyst Lifetimes? Angewandte Chemie 120, 48, 9443-9446.
24 Cafun J.-D., Kvashnina K.O., Casals E., Puntes V.F., Glatzel P. (2013) Absence of $\mathrm{Ce}^{3+}$ Sites in Chemically Active Colloidal Ceria Nanoparticles, ACS Nano 7, 12, 10726-10732.

25 Harris W.M., Lombardo J.J., Nelson G.J., Lai B., Wang S., Vila-Comamala J., Liu M., Liu M., Chiu W.K.S. (2014) Three-Dimensional Microstructural Imaging of Sulfur Poisoning-Induced Degradation in a Ni-YSZ Anode of Solid Oxide Fuel Cells, Sci. Rep. 4, 5246.

26 Jonesa K., Fengb H., Lanzirottic A., Mahajan D. (2005) Mapping metal catalysts using synchrotron computed microtomography (CMT) and micro-X-ray fluorescence (XRF), Topics in Catalysis 32, 3-4, 263-272.

27 Hill A.H. (2013) A new gas system for automated in situ powder diffraction studies at the European Synchrotron Radiation Facility, Journal of Applied Crystallography 46, 2, 570-572.

28 Andrieux J., Chabert C., Mauro A., Vitoux H., Gorges B., Buslaps T., Honkimäki V. (2014) A high-pressure and hightemperature gas-loading system for the study of conventional to real industrial sized samples in catalysed gas/solid and liquid/solid reactions, Journal of Applied Crystallography 47, $1,245-255$.

29 van Beek W., Safonova O.V., Wiker G., Emerich H. (2011) SNBL, a dedicated beamline for combined in situ X-ray diffraction, X-ray absorption and Raman scattering experiments, Phase Transitions 84, 8, 726-732.

30 Mitchell E.P., Boller E., Gordon E.J., Leonard G.A., Monaco S. (2011) The Industrial Research Program at the European Synchrotron Radiation Facility: The Past, the Present, and Challenges for the Future, Synchrotron Radiation News 24, 6, 18-23.

31 Suzuki, M. (2014) Recent Trends in Industrial Applications, Synchrotron Radiation News 27, 3, 2.

32 Ackland R.G., Garrod R.I., Richardson J.F. (1950) Summarized Proceedings of Conference on "X-Rays in Industry" Melbourne, Australia, November, 1949, British J. Appl. Phys. 1, 9, 217-224.
Manuscript submitted in October 2014
Manuscript accepted in November 2014
Published online in March 2015

Cite this article as: J.M. Hudspeth, K.O. Kvashnina, S.A.J. Kimber and E.P. Mitchell (2015). Synchrotron X-Ray Scattering as a Tool for Characterising Catalysts on Multiple Length Scales, Oil Gas Sci. Technol 70, 3, 429-436. 